\title{
Los indios del Nuevo Mundo en el esquema cristiano de la historia universal según fray Diego Durán
}

\author{
Sergio Ángel Vásquez Galicia*
}

Recibido el 26 de diciembre de 2018; aceptado el 7 de mayo de 2019

\section{RESUMEN}

Para los investigadores contemporáneos es claro que la Historia de las Indias de la Nueva España e islas de Tierra Firme (1581), de Diego Durán, es una obra fundamental para el conocimiento del mundo náhuatl prehispánico y del proceso de evangelización en el centro de México a finales del siglo XVI. Sin embargo, pocos se han dedicado a comprender esta crónica como un producto histórico. El objetivo de este artículo es explicar, desde la perspectiva del análisis historiográfico, cómo el apego que el fraile dominico tuvo hacia la Nueva España se manifestó en la Historia de las Indias, tanto en sus elogios a la naturaleza americana y a las virtudes de los indios, como en su esfuerzo por explicar que los indios del Nuevo Mundo también eran hijos de Dios y participaban del plan divino de salvación. Este análisis hace explícito el sentimiento criollo que arraigó en Durán y contribuye a la comprensión del fondo teológico que le permitió colocar a su tierra novohispana en el devenir cristiano universal.

Palabras clave: Diego Durán, análisis historiográfico, cronistas dominicos, criollismo, Topiltzin-santo Tomás.

* Colegio de Historia, Facultad de Filosofía y Letras, unAm, Ciudad de México, México. Correo electrónico: tlacateotl@gmail.com. ORCID: https://orcid.org/0000-0002-1901-220X. 


\title{
The Indians of the New World in the Christian Scheme of Universal History According to Fray Diego Durán
}

\begin{abstract}
For contemporary historians and researchers it is clear that the Historia de las Indias de la Nueva España e islas de Tierra Firme (1581) by Diego Durán is a fundamental work for the knowledge of the pre-hispanic nahuatl world and the process of evangelization at the center of Mexico in the end from the 16th century. However, few of them have devoted themselves to understanding this chronicle as a historical product. The objective of this article is to explain, from the perspective of historiographical analysis, how the attachment that the Dominican friar had towards New Spain was manifested in his work. First, he praise of the American nature and the virtues of the Indians. Second, in his effort to explain that the Indians of the New World were also sons of God and participating in the divine plan of salvation. In this analysis makes explicit the argue about the Creole feeling that took root in Durán and how this contributes to the understanding of the theological background that allowed him to include the New Spain in the Christian scheme of universal history.

Key words: Diego Durán, Historiographical Analysis, Dominican Chroniclers, Criollismo, Topiltzin-santo Tomás.
\end{abstract}

工 a Historia de las Indias de Nueva España e islas de Tierra Firme del dominico Diego Durán (ca. 1537-1588) es una de las fuentes de mayor importancia para conocer las circunstancias en las que se encontraba el proceso de evangelización en el centro de México hacia el último cuarto del siglo XVI, pues Durán fue uno de los frailes que con más empeño denunció los malos resultados en dicha labor, ya que advirtió que escondido en las celebraciones cristianas, el culto a los dioses de los indios seguía vivo. Por ello sentenció que no era posible enseñar a los naturales a conocer al verdadero Dios si primero no se borraban totalmente de su memoria las antiguas ceremonias, de la misma forma en que no era posible "darse bien la sementera del trigo y los frutales en la tierra montuossa y llena de breñas y maleça sino estuviesen primero gastadas todas las raizes y cepas que ella de su natural producia”. ${ }^{1}$

1 La Biblioteca Nacional de España ha puesto en su portal de Internet la digitalización del manuscrito original de la Historia de las Indias de Diego Durán. El acceso a este manuscrito me ha permitido observar que la paleografía realizada por Francisco González Vera, para la edición de José Fernando Ramírez, se apega ampliamente al sentido del original. Así, para 
Gracias a la profundidad con la que Durán indagó en la historia y costumbre de los naturales, principalmente de los mexicas tenochcas, su Historia de las Indias también se cuenta entre las principales fuentes para conocer las particularidades del mundo náhuatl antes del arribo de los castellanos. Su crónica, ${ }^{2}$ en este sentido, sólo es comparable con obras de la envergadura del Códice florentino (1577), de fray Bernardino de Sahagún, o la Monarquía Indiana (1615), de fray Juan de Torquemada, sin embargo, la Historia de las Indias es más que una cantera de dónde extraer ciertos datos acerca del pasado indígena. Esta crónica también es un producto histórico y en ella han quedado reflejadas las circunstancias de su creador: su formación intelectual y bagaje cultural, su idea acerca de la historia y del trabajo del historiador, sus inquietudes y preocupaciones vitales, e incluso, la idea que tenía acerca de sí mismo, es decir, de su identidad. ${ }^{3}$

En las siguientes páginas indagaremos en cómo Durán interpretó la historia indígena antigua en función del esquema de la historia universal cristiana, porque es un aspecto fundamental para entender la obra del dominico como producto histórico. Algunos autores contemporáneos, como Guy Rozat, Elsa Cecilia Frost y Miguel León-Portilla, ${ }^{4}$ han abordado este tema a partir de un conjunto de obras novohispanas. Por su parte, Sylvie Peperstraete sólo lo enunció para el caso de la Historia de las Indias, ${ }^{5}$ por lo cual, un estudio de mayor puntualidad, como el que aquí proponemos, es pertinente.

fines prácticos, en este artículo las citas serán tomadas de la edición de Ramírez. Durán, Historia de las Indias de Nueva España e islas de Tierra Firme, v. II, "Prólogo”, p. 13. El lector puede consultar el manuscrito original de la Historia de las Indias en: http://bdh-rd.bne.es/viewer.vm?id=0000169486\&page=1 [Consultado el 15 de noviembre de 2018].

2 Para referirnos a la obra de Durán emplearemos, indistintamente, la palabra “crónica” o "historia”, pues, como la ha demostrado José Rubén Romero Galván, para la época estos términos, en tanto se referían a hechos del pasado, eran considerados sinónimos. Romero, "La historia según Chimalpahin", p. 190.

3 Sobre este asunto sigo algunas de las ideas de Edmundo O’Gorman y Ramón Iglesia respecto a la naturaleza del análisis historiográfico. De ellos sólo daré dos referencias: O’Gorman, "La conciencia histórica en la edad Media”, pp. 29-66, e Iglesia, "Sobre el estado actual de las ciencias históricas”, pp. 26-31.

4 Rozat, Indios imaginarios e indios reales en los relatos de la conquista de México. Sobre este trabajo debemos comentar que no coincidimos con su autor respecto a que los relatos indígenas de la conquista sólo se explican a partir de "una matriz simbólica" totalmente medieval (p. XII). Frost, La Historia de Dios en las Indias. Visión franciscana del Nuevo Mundo y León-Portilla, "El indio visto por los frailes del siglo XVI”, pp. 281-295.

5 Peperstraete, La "Chronique $X$ ": reconstitution et analyse d'une source perdue fondamentale sur la civilisation Aztèque, d'après l'Historia de las Indias de Nueva España de D. Durán (1581) et la Crónica Mexicana de F.A. Tezozomoc (ca. 1598), pp. 20-23. 
Somos conscientes de que el esfuerzo por incluir a los indios del Nuevo Mundo en el devenir cristiano universal no fue un evento exclusivo de nuestro autor; desde que los españoles llegaron a las tierras que fueron conocidas como América, religiosos, conquistadores, funcionarios reales y la nobleza indígena novohispana echaron mano de dicho esquema para explicar la historia de estas tierras. Sin embargo, en el caso de Durán consideramos que esta interpretación también fue una respuesta al entrañable cariño que el dominico adquirió por la tierra novohispana, a la que tomó como su patria. Es decir, al incluir la historia de los indios en el devenir que según la concepción cristiana inició con el pecado original y culminará con el juicio final, Durán intentó mostrar que la Nueva España formaba parte, tanto como cualquier otro pueblo cristiano en el mundo, del fin trascendente de la humanidad, el de la salvación de las almas. En este sentido, podemos decir que en la Historia de las Indias ya se vislumbraba el proceso mediante el cual el americano fue tomando conciencia de la singularidad de su ser; fenómeno al cual se le ha llamado criollismo. Ese es el contexto que nos permite comprender la obra del dominico.

\section{DEL CRIOLLISMO}

El criollismo, tal como lo planteara Edmundo O'Gorman, es un concepto que da cuenta del proceso histórico por el cual ciertos sectores de la sociedad novohispana —religiosos, descendientes de conquistadores e indígenas de élite - tomaron conciencia de su singularidad como americanos. ${ }^{6}$ En este sentido, criollo no es solamente el americano de padres europeos, "sino[...] quien no precisamente haya nacido aquí, pero que se haya sentido a los aquí nacidos....". ${ }^{7}$ Un mestizo, un indígena o un español pueden ser criollos, pues ello no depende de la raza, sino de su participación en esta toma de conciencia.

El proceso al que aquí nos referimos fue de larga duración ${ }^{8}$ e inició muy temprano, prácticamente "al otro día de la Conquista", ${ }^{9}$ pues su nacimiento estuvo marcado por el contacto entre los grupos indígenas de América y los españoles. Uno de los aspectos más importante de este evento es que fue generado por la necesidad del americano por definir su identidad, ya que sus circunstancias históricas lo ubicaron en una aparente encrucijada, "la de cómo pertenecer en cuerpo y alma a España la vieja sin dejar de ser en alma

O’Gorman, Meditaciones sobre el criollismo, p. 23.

Manrique, "Del barroco a la ilustración", p. 433.

8 Tuvo vida durante los tres siglos de historia novohispana. Alberro, El águila y la cruz. Orígenes religiosos de la conciencia criolla, p. 27.

9 Paz, "Prefacio", p. 15. 
y cuerpo hijo de la Nueva España”. ${ }^{10}$ Por ello, es atinado considerar al criollismo como un fenómeno de dimensiones ontológicas. ${ }^{11}$

Las primeras expresiones del criollismo quedaron plasmadas en la exaltación que los americanos hicieron de la naturaleza novohispana, sin embargo, una de sus principales preocupaciones fue demostrar que su tierra también formaba parte del Plan Divino. ${ }^{12}$ Eso fue lo que llevó a cabo Durán con su interpretación de la historia indígena.

\section{FRAY DiEGo DURÁN}

Gracias a un documento que el historiador mexicano Francisco Fernández del Castillo (1864-1936) encontró en el Ramo de Inquisición del Archivo General de la Nación de México sabemos que Diego Durán nació en Sevilla, España, alrededor de $1537 .^{13}$ No tenemos noticias de quiénes fueron sus padres, ni de cómo fueron sus primeros años de vida, ${ }^{14}$ lo único seguro es que llegó a Nueva España apenas iniciada su infancia y que radicó en Tetzcoco, pues él mismo nos dice en su obra que "ya que no nacieron allí los dientes, vínelos allí á mudar". ${ }^{15}$

Coincido con Rosa Camelo Arredondo y José Rubén Romero Galván en la posibilidad de que fuera a partir de los constantes juegos con los niños indígenas tetzcocanos que Durán aprendiera el náhuatl y entrara en contacto íntimo con la cultura de los naturales. ${ }^{16}$ Como constancia del dominio de dicha lengua, queda el testimonio de haberse desempeñado ante el Tribunal del Santo Oficio de la Inquisición como intérprete de una india que sólo

10

O'Gorman, Meditaciones..., p. 27.

12 No es posible abordar con mayor detalle cuáles fueron las circunstancias económicas y políticas que alimentaron el criollismo. Para ello remitimos al lector a los siguientes textos; Vásquez, la Historia de las Indias, de Diego Durán y Los albores del criollismo y Vásquez "México Tenochtitlan, raíz, ombligo y corazón de esta máquina mundial. El criollismo en la Historia de las Indias de Diego Durán” (en prensa).

13 Fernández, "Fray Diego Durán. Aclaraciones históricas", p. 225. El documento, ubicado en el volumen 232, fojas 227-251, es una denuncia en contra del dominico fray Andrés de Ubilla y vino a disipar todas las dudas sobre la nacionalidad de Durán de quien se creía, por noticias de Dávila Padilla, que era mexicano. Fernández del Castillo explica este supuesto como un error en la lectura de la información que ofrece el cronista de la orden, pues al llamar a Durán "hijo de México" no se refería a que había nacido en México, sino que era hijo de la provincia de Santiago de México. Véase Dávila, Historia de la fundación y discurso de la provincia de Santiago de México de la orden de predicadores [1596], p. 653.

14 Sandoval, “La relación de la conquista de México en la historia de Fray Diego Durán”, pp. 51-54.

15 Durán, op. cit., v. I, “Tratado de historia”, cap. II, p. 64.

16 Camelo y Romero, “Estudio preliminar”, en íbid., v. I, p. 43. 
hablaba mexicano. ${ }^{17} \mathrm{Y}$ de su contacto con el mundo indígena ha quedado una buena cantidad de anécdotas a lo largo de su obra, como aquella en la que confiesa que de pequeño comió etzalli, "que es unas puchas de frijol con maiz cocido entero dentro una comida tan sabrossa para ellos y tan deseada y apetecida que no en valde tenía día particular y fiesta para ser solemnizada”. ${ }^{18}$

Los escasos datos sobre su vida sólo nos permiten ubicar a Durán nuevamente hasta 1556, cuando, con alrededor de 19 años de edad, hizo profesión como fraile en el convento de Santo Domingo de México. ${ }^{19}$ Seguramente la efervescencia que vivía el proceso evangelizador en ese momento lo inclinó por la vida religiosa; sin embargo, sobre su elección del sayo negro y blanco de los dominicos se han planteado varias posibilidades.

Fernando Sandoval considera que Durán escogió esta orden "quizá por tener amistad con padres dominicos que encausarían su vocación, o bien porque fuera la que más se apegaba a su carácter por ser una orden de filósofos y escritores”. ${ }^{20}$ Por su parte, Pilar Máynez Vidal señala que existe la posibilidad de que Durán conociera a fray Domingo de Betanzos y que éste influyera en su inclinación por la Orden de Predicadores, ${ }^{21}$ no obstante, hay que recordar que Betanzos simpatizaba más con la vida de observancia monacal que con las labores apostólicas entre los naturales, las cuales fueron una prioridad para nuestro autor. ${ }^{22}$

Lo más probable, entonces, es que Durán se inclinara por la Orden de los Dominicos porque era la que mejor respondía a sus inquietudes y necesidades; pero no tanto por privilegiar la meditación teológica, como menciona Sandoval, sino por su dedicación a la salvación de almas mediante la prédica evangélica. ${ }^{23}$ Como quiera que haya sido, tres años después de haber hecho profesión, en septiembre de 1559, fue nombrado diácono del convento de la ciudad de México ${ }^{24}$ y un par de años más tarde fue asignado al convento de

\footnotetext{
Colston y Paredes, “Un servicio de fray Diego Durán a la Inquisición”, pp. 41-44.

Durán, op. cit., v. II, “Calendario antiguo”, p. 260.

Camelo y Romero, op. cit., v. I, p. 21.

Sandoval, op. cit., p. 53.

Máynez, Fray Diego Durán, p. 15.

22 Cabe mencionar que sabemos que el jesuita Juan de Tovar fue deudo de nuestro cronista, por lo cual la influencia familiar para inclinarse por una orden en particular tampoco es una vía segura. "Correspondencia entre los padres José de Acosta y Juan de Tovar”, p. 33.

23 Según Daniel Ulloa, “...la misión específica de la Orden de Predicadores es la salvación de las almas por medio de la predica evangélica y la alabanza divina, y de ese modo la institución preconizaba como prácticas particulares el estudio y la meditación de las Sagradas Escrituras junto con la recitación solemne del oficio divino". Ulloa, Los predicadores divididos, p. 149.

24 Sandoval, op. cit., p. 54. La información que proporciona Sandoval sobre la vida de Durán proviene de las Actas dominicas.
} 
Oaxaca. ${ }^{25}$ Su estancia en este último lugar debió de ser breve, pues no se cuenta con ningún registro de la orden que atestigüe su presencia. ${ }^{26}$

Según Fernando Horcasitas y Doris Heyden, luego de su paso por Oaxaca, durante más de veinticinco años (de 1561 a 1586) Durán "estuvo de convento en convento en la región del Marquesado". ${ }^{27}$ Sus desplazamientos por esta zona (Puebla, Morelos y el Estado de México) le permitieron apreciar la belleza natural de la tierra americana y sus impresiones al respecto las dejó plasmadas en su obra. ${ }^{28}$

Posteriormente, volvemos a tener noticias certeras del dominico en 1586, cuando, ya instalado en la ciudad de México, fue intérprete de la india Madalena Marta ante el tribunal del Santo Oficio y, en 1587, cuando levantó una denuncia contra el provincial de la orden, fray Andrés de Ubilla, acusándolo de luteranismo y tratos con el demonio, entre otras cosas. ${ }^{29}$ Por el documento en que se consigna este último evento sabemos que Durán fue vicario en Hueyapan, Morelos, lugar donde posiblemente terminó de redactar su Historia de las Indias en 1581. ${ }^{30}$

Finalmente, por las Actas dominicas sabemos que el 8 de mayo de 1587, un mes antes de hacer su denuncia contra Ubilla, nuestro autor se encontraba muy enfermo. ${ }^{31}$ Diego Durán murió en la ciudad de México en 1588, a la edad de 51 años.

Sobre la Historia de las Indias sólo diremos que está compuesta por un tratado de "Historia" (1581), otro de "Los ritos y ceremonias en las fiestas de los dioses" (1576-1579) y un "Calendario Antiguo" (1579), y que cuentan con más de un centenar de ilustraciones en color. La obra permaneció inédita hasta el último cuarto del siglo XIX, cuando José Fernando Ramírez y Gumecindo Mendoza la dieron a la imprenta (1867-1880). El manuscrito original actualmente es resguardado por la Biblioteca Nacional de España.

26

Ídem.

Máynez, op. cit., p. 15.

Heyden y Horcasitas, "Biographical note”. Tomado de íbid., p. 16.

Más adelante daré un ejemplo de esto.

Fernández, op. cit., pp. 223-229.

Sobre esta posibilidad véase, Vásquez, La historia de las Indias, pp. 52-56.

Actas dominicas, sin folio. Citadas por Sandoval, op. cit., p. 56. Esta condición la confirma Dávila, op. cit., p. 653. Camelo y Romero creen posible que para este momento Durán se encontrara afectado de sus facultades mentales y por ello levantara la denuncia en contra de su provincial, "Fray Diego Durán”, p. 230. Lo que señalan las Actas dominicas parece dar sustento a la propuesta: "Que nuestro padre haga guardar el parecer que dieron los médicos acerca de la enfermedad del padre Fray Diego Durán, por los inconvenientes que dello resultan”. Actas dominicas, sin folio, citadas por Sandoval, op. cit., p. 56. 


\section{LOS INDIOS DEL NUEVO MUNDO Y LA HISTORIA UNIVERSAL CRISTIANA}

La presencia de América obligó al europeo a explicar la existencia de algo no previsto en su concepción del mundo. Sin embargo, las implicaciones de este hecho fueron más profundas para las personas que hicieron de ella su hogar, como es el caso de los primeros pobladores europeos de la que fue llamada Nueva España. Para ellos no se trató únicamente de hacer inteligible dicha realidad a los hombres del Viejo Continente, sino de explicarse a sí mismos como parte del Nuevo Mundo. Desde luego, dicha explicación se llevó a cabo a partir de las ideas válidas para los cristianos y eso implicó colocar a las tierras americanas dentro del marco de la historia universal cristiana. Eso fue lo que hizo Durán.

\section{EL ORIGEN DEL INDIO}

La Historia de las Indias es una obra fundamentalmente de tradición mexica tenochca. En ella, su autor incluyó a los indios en el plan divino de salvación retomando dos aspectos fundamentales de la conciencia histórica de dicho grupo. El primero fue la idea acerca de su origen, y el segundo, el vínculo que se adjudicaban los habitantes de Tula Xicocotitlan (900-1220 d.C.) como sus herederos culturales. El primer aspecto fue primordial para demostrar que los naturales eran criaturas de Dios y, por lo tanto, podían participar de la redención de las almas; y el segundo, que abordaremos más adelante, para explicar la llegada del cristianismo.

Sobre el origen de los indios el dominico destacó lo siguiente:

Para tratar de la cierta y verdadera relacion del orígen y principio destas naciones indianas, á nosotros tan abscondido y dudoso, que para poner la mera verdad fuera necesaria alguna revelacion divina ó espíritu de Dios que lo enseñara y diera á entender; empero, faltando esto, será necesario llegarnos á las sospechas y conjeturas, á la demasiada ocasión que esta gente nos da con su bajísimo modo y manera de tratar, y de su conversion tan baja, tan propia á la de los judíos, que podriamos ultimadamente afirmar ser naturalmente judíos y gente hebrea, y creo no incurriria en capital error el que lo afirmase... ${ }^{32}$

De esta cita se pueden destacar varios puntos importantes. Para comenzar, al señalar que el origen del indio era un tema "dudoso", el dominico aceptó que, en efecto, la presencia de las tierras americanas no había sido 
contemplada en el esquema del mundo conocido. No obstante, también señaló claramente que eso sucedía porque el conocimiento de un evento tan extraordinario pertenecía exclusivamente a Dios; de tal forma que para ser comprendido por el hombre hacía falta "alguna revelación divina".

Evidentemente, a noventa años del descubrimiento de América, para Durán era claro que dicha revelación no llegaría. Así que, de la misma forma en que lo hicieron otros religiosos de su tiempo, como fray Toribio de Benavente, "Motolinía" (1482-1569), fray Gerónimo de Mendieta (1525-1604) o los ya mencionados Sahagún y Torquemada, el dominico recurrió a la especulación ("sospechas y conjeturas") basada en las Sagradas Escrituras para explicar el tema.

Nuestro autor no reparó mucho en emitir su opinión, sobre todo al darse cuenta de que los propios naturales "ignoran su orígen y principio". ${ }^{33}$ Así, a partir de una primera caracterización de la naturaleza de los indios, a quienes les atribuyó un "bajísimo modo y manera de tratar" y una "conversion tan baja”, de inmediato los identificó como judíos.

Para esto, Durán seguramente tuvo como base la idea que los españoles se forjaron de los judíos durante el proceso que culminó con su expulsión de Castilla y Aragón, la cual sucedió precisamente el mismo año en que se descubrió América. Por ello, señala acertadamente Jacques Lafaye:

Si por efecto de una simplificación similar los colonos de América se convencían de que los indios eran judíos, encontraban de inmediato a su disposición una serie de comportamientos idénticos a los que habrían tenido ante los judíos de Castilla o de Aragón. En ambos casos se trataba de superar el cambio de costumbres del Nuevo Mundo, asimilando sus poblaciones y su cultura con otras mejor conocidas... ${ }^{34}$

Sin embargo, los argumentos que robustecieron la identificación de los naturales del Nuevo Mundo con los hombres del pueblo de Israel tuvieron como base una imagen del judío construida a partir de la interpretación del Antiguo Testamento. Por eso Durán señaló que "para probacion de lo qual será testigo la Sagrada Escriptura, donde clara y abiertamente sacaremos ser verdadera esta opinion, y algunas razones bastantes para ello daremos”. ${ }^{35}$

El primer elemento que el dominico destacó al respecto fue el siguiente:

33 Ibíd., v. I, “Tratado de historia”, cap. I, p. 54.

34 Lafaye, Quetzalcóatl y Guadalupe, p. 91.

35 Durán, op. cit., v. I, “Tratado de historia”, cap. I, p. 53. 
...tendremos por principal fundamento el ser esta nacion y gente indiana advenediza, de estrañas y remotas regiones, y que en su venida á poseer esta tierra, hizo un largo y prolijo camino, en el cual gastó muchos años y meses para llegar á ella, como de su relacion y pinturas se colige, y como de algunos viejos ancianos, de muchos dias, he procurado saber para sacar esta opinion... ${ }^{36}$

Comparar el mundo americano con el europeo implicó “desde un principio un acercamiento y una familiaridad con el primero”. ${ }^{37}$ En este caso, para explicar el origen de los indios, Durán recurrió al planteamiento de analogías entre la historia de los naturales y la del pueblo judío. Para ello, además de las Sagradas Escrituras, el fraile apeló a la tradición histórica indígena, a la cual también le adjudicó cierta autoridad por tener como fundamento tanto las antiguas pictografías como los testimonios orales de la gente más sabia entre los naturales: los ancianos.

Según el dominico, estas obras le certificaban que ambos pueblos compartían la historia de un largo y complicado trayecto desde lugares lejanos hasta la tierra prometida. Evidentemente, en este caso lo que nuestro cronista hizo fue asimilar la información relativa a las migraciones indígenas del Posclásico mesoamericano (900-1521 d. C.) registradas en los códices ${ }^{38}$ y en la memoria de sus informantes, con el éxodo judío narrado en el Antiguo Testamento. ${ }^{39}$ Durán no tuvo dudas de la correlación entre ambos relatos, por eso mencionó que los sufrimientos que vivieron los naturales en su trayecto coincidían con "aquel largo y prolijo camino que los hijos de Israel anduvieron desde Egipto hasta la tierra de promisión, tan al propio y tan al vivo, que bastará trasladar aquí el Exodo ó Levitico..." 40

Además del largo camino, Durán interpretó otros tres sucesos de las migraciones indígenas para ajustarlos con el éxodo judío. En primer lugar, el sometimiento que según las fuentes vivían los mexicas en Aztlan; ${ }^{41}$ poste-

36 Ídem.

Alberro, op. cit., p. 21.

38 No sabemos qué códices consultó el dominico, sin embargo, actualmente quedan varios que narran esta migración. Nosotros sólo daremos referencia de tres de ellos: Tira de la peregrinación [Primeras décadas del siglo XVI]; Codex Azcatitlan [Finales del siglo XVI].

39 También Peperstraete ha destacado el interés de Durán por establecer analogías entre el Éxodo y la migración mexica. Peperstraete, op. cit., p. 21.

40 Durán, op. cit., v. I, “Tratado de historia”, cap. I, p. 56. Seguramente pictografías similares a la plancha 9 del Códex Azcatitlan, en donde se puede observar a los mexicas transitando por lugares agrestes y llenos de animales salvajes, pudo servir a Durán para hacer referencia a los sufrimientos padecidos por el pueblo de Israel en su éxodo por el desierto.

41 Por ejemplo, la Historia de la venida de los mexicanos de Cristóbal del Castillo dice: "Los que allá están haciendo su hogar, los que lo llaman su población, los que gobiernan en Aztlán Chicomóztoc son los aztecas chicomoztocas. Y sus macehuales — gente del puebloeran los mecitin, los ribereños, los pescadores de los gobernantes aztecas: ciertamente ellos eran sus macehuales, sus pescadores. Y sus gobernantes los maltrataban mucho, mucho los 
riormente, el necesario paso por agua para abandonar su antigua patria, ${ }^{42} \mathrm{y}$ finalmente, la idea de pueblo elegido, al cual su dios patrono Huitzilopochtli le había prometido llegar a una tierra en la que gobernarían sobre el resto de las naciones. ${ }^{43}$ Esta información fue interpretada por el dominico de la siguiente forma:

[cuentan de un gran varón] que después de auer pasado grandes aflicciones y persecuciones de los de la tierra, que juntó toda la multitud de gente que era de su parcialidad, y que les persuadió á que huyesen de aquella persecución á una tierra donde tuviesen descanso; y que haviéndose caudillo de aquella gente, se fue a la orilla de la mar, y que con una vara que en la mano traía, dió en el agua con ella y que luego se abrió la mar y entraron por allí él y sus seguidores, y que los enemigos, viendo echo camino se entraron tras él, y que luego se tornó la mar á su lugar, y que nunca más tuvieron noticia dellos. ¡Qué más clara raçon se pude dar de questos sean judíos, que ver quán manifiestamente y al propio relaten la salida de Egipto, el dar Moisés con la vara en la mar, el abrirse y hacerse camino, el entrar Pharaon con su ejército tras ellos y volver Dios las aguas á su lugar, donde todos quedaron en el profundo ahogados. ${ }^{44}$

Como podemos notar, en esta cita Durán identificó a Huitzilopochtli con Moisés y a la migración mexica con el éxodo del pueblo de Israel. Estas supuestas similitudes no le dejaban lugar a dudas de que los naturales eran de linaje hebreo. Así que su siguiente paso fue buscar en las Sagradas Escrituras la referencia que sustentara el paso de los judíos a América. Para esto, el dominico señaló lo siguiente:

hacían tributar". Castillo, Historia de los mexicanos y de otros pueblos e historia de la conquista [1600], p. 91.

Por ejemplo, en la lámina I de la Tira de la peregrinación, en la esquina superior derecha del Mapa Sigüenza y en la lámina II del Códex Azcatitlan se puede observar a Huitzilopochtli hablando con los mexicas (lo cual se identifica por las volutas que salen de su pico), y posteriormente podemos ver la salida del pueblo cruzando una gran laguna. Además la Crónica mexicáyotl dice: "Los mexicanos salieron de allá del lugar llamado Aztlan, el cual se halla en mitad del agua; de allá partieron para acá los que componían los siete calpulli”. Alvarado Tezozómoc, Crónica mexicáyotl [1610], p. 15.

43 Por ejemplo, según Del Castillo, Huitzilopochtli le dijo a su pueblo: “¡Oh, mi macehual! ¡Oh, Huitzilópoch! En verdad me causas mucha compasión tú, y mucha todos vosotros mis mecehuales, los ribereños mecitin. Pero ya fui a observar dónde está el lugar bueno y recto, el único lugar que es como éste, donde también hay un lago muy grande, donde todo crece, todo lo que habréis de necesitar. Nada se perderá de los que aquí estáis, [pues] todo allá también crece, porque no quiero que aquí os destruyan. Pero allá donde os doto, donde os prometo tierras, es en la tierra de otros, pues ya por doquier están asentados, y ninguna parte está desocupada [...] Y si hiciereis todas las ofrendas, si hiciereis todo lo que ante mí prometáis, ciertamente allá donde os acompañe, donde os iré a sentar, allá gobernarán...”. Castillo, op. cit., p. 95.

44 Durán, op. cit., v. I, “Tratado de historia”, cap. I, pp. 56-57. 
Confirmo mi opinion y sospecha de que estos naturales sean de aquellas diez tribus de Israel, que Salmanasar, Rey de los Asirios, cautivo y transmigró de Asiria en tiempo de Oseas, Rey de Israel, y en tiempo de Ezquías, Rey de Jerusalem, como se podrá ver en el Cuarto Libro de los Reyes, cap. 17, donde dize que fue trasladado Israel de su tierra á los Asirios, hasta el dia de hoy, etc., de los quales dize es tierra remota y apartada que nunca había sido auitada. A la qual auia largo y prolijo camino de año y medio, donde agora se hallan estas gentes de todas las islas y tierra firme del mar Océano, hácia la parte de Ocidente. ${ }^{45}$

En 4 Reyes 17:6, se menciona que "El año noveno de Oseas, el rey de Asiria tomó a Samaria y llevó cautivos a sus habitantes a Asiria, haciéndoles habitar en Jalaj y Jabor, junto al río Gozán y en las ciudades de la Medias”. La causa fue que el pueblo de Israel se dio a todos los pecados “...hasta que Yavé arrojó a Israel lejos de su presencia, como lo había anunciado por todos sus siervos los profetas. E Israel ha sido llevado cautivo lejos de su tierra, a Asiria, donde está hasta el día de hoy” (4 Reyes 17:22-23). ${ }^{46}$

Sin embargo, este texto bíblico sólo sirvió a Durán para dar entrada al tema del cautiverio de las tribus. Para completar su relato, nuestro autor recurrió a otro escrito que, a partir de la cuarta sesión del Concilio de Trento (8 de abril de 1548), fue considerado apócrifo, ${ }^{47}$ me refiero a 4 Esdras, en cuyo capítulo 13:39-46 dice:

$\mathrm{Y}$ porque le viste que recogia asi otra muchedumbre pacifica, sabràs, que estos son los diez Tribus, que fueron llevados en Cautiverio, en tiempo del Rei Oseas, al qual llevó cautivo Samanasar, Rei de los Asyrios, i à estos los pasò à las otras parte del Rio, i fueron trasladados à otra Tierra. Ellos tuvieron entre sì acuerdo, i determinación de dejar la multitud de los Gentiles, i de pasarse à otra Region mas apartada, donde nunca habitò el Genero Humano, para guardar siquiera allí su Lei, la qual no havian guardado en su Tierra. Entraron, pues, por unas entradas angostas del Rio Eufrates, porque hiço el Altisimo entonces con ellos sus maravillas, y detuvo las corrientes del Rio, hasta que pasasen, porque por aquella Region era el camino mui largo de Años i medio, i llamase aquella Region Arsareth. Entonces habitaron allí hasta el ultimo tiempo... ${ }^{48}$

Ibíd., v. I, “Tratado de historia”, cap. I, p. 54.

46 Los textos bíblicos serán retomados de la siguiente edición: Sagrada Biblia, 40ª edición, versión directa de las lenguas tradicionales por Eloino Nacar Fuster y Alberto Colunga Cueto, Madrid, Editorial Católica, 1980 (Biblioteca de Autores Cristianos).

48 Existen varias traducciones recientes de 4 Esdras; Florentino García Martínez compara una de Gabriel Nápole, que aparece en Liber Ezrae Quartus, de 1998, y otra de Domingo Muñoz León, del libro Apócrifos del Antiguo Testamento de 2009. Véase ibíd., pp. 176-177. Nosotros, para alejarnos lo menos posible del contexto de Durán, hemos retomado el texto que 
Como podemos notar, de este texto Durán retomó tres puntos para complementar su identificación de los indios como judíos; en primer lugar, que las tribus de Israel fueron trasladadas a tierras apartadas y que nunca habían sido habitadas por el género humano, es decir, América; en segundo lugar, que el camino hacia dichas tierras había sido largo y prolijo, de año y medio, y finalmente, que las tribus "habitaron allí hasta el último tiempo", es decir, que era la gente que habían encontrado los españoles en el Nuevo Mundo.

No debe sorprender que Durán recurriera a 4 Esdras para sostener su propuesta, pues a pesar de haber quedado fuera de los textos canónicos, durante los siglos XVI y XVII gozó de gran crédito. Así lo atestigua el jesuita José de Acosta, quien en su Historia natural y moral de las indias (1590) afirma que la hipótesis del linaje judío de los indios, basada en dicho texto, era "opinión de muchos". ${ }^{49}$ De hecho, en 1607 Gregorio García, en su Origen de los indios del Nuevo Mundo, defendió tanto el linaje hebreo de los indios, como la autoridad del apócrifo que daba sustento a la hipótesis, sobre el cual dice: "el cual Libro, aunque lo que se dice en él no es canonico, ni de Fè Catolica, à lo menos tiene tanta autoridad como de vn Doctor Grave". ${ }^{50} \mathrm{Y}$ todavía para 1615 Torquemada señalaba que aunque 4 Esdras no era un texto canónico era aceptado "como à cosa buena". ${ }^{51}$

Como quiera que sea, es claro que en dicho libro el dominico encontró los elementos más claros para sostener la hipótesis del linaje hebreo de los indios. Esto lo podemos considerar como algo bastante original, pues aunque tenemos conocimiento de que el primero en manifestar esta opinión fue un personaje identificado como el Doctor Roldán, quien en 1540 escribió un pequeño tratado que fue titulado "Razones por las que el Doctor Roldán basaba su afirmación de que las Indias estuvieron pobladas por las diez tribus de Israel”, ${ }^{52}$ no tenemos certeza de que Durán conociera dicho manuscrito. ${ }^{53}$

cita Gregorio García, Origen de los indios del Nuevo Mundo, Libro tercero, cap. I, p. 80. La primera edición de esta obra es de 1607; nosotros citamos la segunda de 1729. Acosta, Historia natural y moral de las Indias [1590], p. 60.

50 García, op. cit., Libro tercero, p. 80.

51 Torquemada, Primera parte de los veinte i un libros rituales i monarchia indiana, México, Porrúa, 1969, v. I, Libro primero, cap. IX, f. 2 (cito el facsimilar de la segunda edición de 1723).

52 Lewis Hanke fue el primero en dar noticia de este documento y señaló que era resguardado en la Biblioteca Provincial y Universitaria de Sevilla, en donde estaba registrado como manuscrito 333. Hanke, The First Social Experiments in America, p. 97. Giuliano Gliozzi analizó dicho documento basado en una copia que se encuentra en el tomo 27, número 280, de la Colección de Don Juan bautista Muñoz. Gliozzi, Adamo e il nuovo mondo, p. 50. Para facilitar la ubicación del documento puede consultarse el Catálogo de la colección de Don Juan Bautista Muñoz, Madrid, v. I, p. 147.

53 Gliozzi considera que Durán se inspiró en el manuscrito de Roldán (op. cit., p. 54). Sin embargo, debemos comentar que aunque el dominico coincidió con algunos argumentos es- 
Una vez que nuestro autor dejó claramente expresada su hipótesis, el siguiente paso fue tratar de consolidarla estableciendo más similitudes entre los hombres del pueblo de Israel y los indios. Así, consideró que si el número de habitantes del Nuevo Mundo era enorme, esto se debía a que "á estas diez tribus [...] tenia Dios prometido por Oseas, c. 1 y 2 y 3 hasta el 13, que los auia Dios de multiplicar como las arenas de la mar". ${ }^{54}$ Además, si el pueblo mexica era el elegido por Huitzilopochtli, sólo lo era como entre los judíos el pueblo de Judá; ${ }^{55}$ si en su migración los mexicas cargaban el bulto de Huitzilopochtli y en cada sitio que paraban le hacían ceremonias y ofrendas, únicamente lo hacían como los hijos de Israel con el Arca de la Alianza; ${ }^{56}$ si los indios celebraban el xiuhmolipilli o la atadura de 52 años, esto lo realizaban "á la mesma manera y modo que antiguamente los judios en su vieja ley celebraban el año del juvileo....; ${ }^{57}$ y si los naturales acostumbraban a practicar el autosacrificio, sólo lo llevaban a cabo "al modo judaico y ley antigua". ${ }^{58}$

grimidos por Roldán para sustentar su tesis, como al referirse a los sacrificios de niños en montes, bosques y árboles sombríos, otros argumentos no aparecen en la obra de nuestro autor. Tal es el caso del cálculo que hace Roldán sobre el tiempo que tardaron los judíos en llegar a América o cuando establece semejanzas entre algún idioma de los naturales y la lengua hebrea. Incluso, aunque ambos citan a Oseas para referirse a la multiplicación de los hijos de Israel (Oseas 2:1), el capítulo que refiere Roldán es errado (Oseas 4), mientras que Durán señala varios (Oseas 1-13). De tal forma que no existe evidencia contundente de que el dominico se basara en el manuscrito de Roldán.

Otra posibilidad es que esta interpretación fuera influencia de Bartolomé de las Casas, pues según Torquemada el otrora obispo de Chiapas era partidario de la tesis sobre el origen judío de los indios. Sin embargo, dicha atribución, basada en un documento cuya autoría creyó del dominico, fue errada. Torquemada, op. cit., v. I, Libro primero, cap. IX, f. 24. De hecho, la tesis del origen judío iría a contrapelo de las ideas de De las Casas, quien, en términos generales, consideró a los indios como gentiles que guiaban su vida por la luz de la razón natural. Sobre esto ver O’Gorman, “Sentido y significación histórica de la Apologética historia sumaria”, v. I, pp. LVIII-LXXIX.

También sabemos que la tesis del origen judío de los indios fue defendida por Gilbert Genebrard en Chronographiae libri quatuor, publicado en 1567. Ver García, op. cit., p. 180. Sin embargo, tampoco hay indicios de que Durán conociera la obra.

Durán, op. cit., v. I, “Tratado de historia”, cap. I, p. 54.

Ibíd., v. I, “Tratado de historia”, cap. II, p. 62.

Ibíd., v. I, “Tratado de historia”, cap. II, p. 68. Esta equiparación entre el bulto del dios Huitzilopochtli y el Arca de la Alianza se puede observar nítidamente en el siguiente párrafo del "Tratado de los ritos y ceremonias": "la qual petaca o basera hacian tanta reuerencia y vmillaçion que al mesmo ydolo teniendola muy tapada con sus cortinas ençima casi con el mesmo aparato y manera que los judios tenian el arca del testamente donde estaban las tablas de la ley y la bara de Aron con el baso de mana asi a la mesma arte tenian en este templo guardada esta arquilla...”. Ibíd., v. II, “Tratado de los ritos y ceremonias”, cap. VII, p. 81.

Ibíd., v. II, “Calendario antiguo”, cap. I, p. 226.

Ibíd., v. II, “Calendario antiguo”, cap. I, pp. 251-252. 
Durán incluso encontró analogías en asuntos tan sutiles como la comida $^{59}$ y la vestimenta. ${ }^{60}$ Sin embargo, para él la prueba definitiva de que América había sido poblada por las tribus perdidas de Israel se encontraba en las costumbres religiosas de los naturales. Así nos dice:

Viéndola tan emparentada y propia á lo de la Sagrada Escriptura, no puedo dejar de, en alguna manera, persuadirme, para probacion de lo qual y para que clara y manifiestamente se vea, quiero que se consideren los Ritos, las idolatrías y supersticiones que tenian; el ir á sacrificar á los montes, bajo los árboles sombríos, á las cuevas y cavernas de la tierra obscura y sombrías; el encender y quemar encienso, el matar sus hijos y hijas y sacrificallos y ofrecellos por víctimas á sus Dioses; sacrificar niños y comer carne umana, matar los presos y captivos en la guerra, todo de cerimonia judaica [...] y lo que mas me fuerça á creer que estos indios son de línea hebrea, es la estraña pertinacia que tienen en no desarraigar de sí estas idolatrías y supersticiones, yendo y viniendo á ellas, como se ve de sus antepasados, como diçe David en el Salmo 105: que en viéndose atribulados de Dios, clamaban á él perdonándolos en su misericordia, pero luego olvidados se volvian a idolatrar... ${ }^{61}$

Como podemos notar, el dominico interpretó las prácticas religiosas indígenas en función de las atribuidas al pueblo de Israel en el Antiguo Testamento. Así sucedió con los rituales que los naturales realizaban en los lugares que consideraban puntos privilegiados para establecer comunicación con sus dioses, como las cuevas, bosques y montañas. Y lo mismo hizo con el sacrificio de niños y la ingesta ritual de carne humana, los cuales se llevaban a cabo en momentos específicos (no de forma cotidiana) y eran considerados por los naturales como eventos fundamentales para propiciar el buen funcionamiento del universo, pero para Durán no eran más que los sacrificios que el pueblo de Israel realizaba para sus ídolos en Canaán (Salmo 105:38). Y finalmente, el culto que los indios rendían a sus dioses le era al dominico tan idolátrico como la adoración al becerro narrada en el Salmo 105:19-20.

59 Por ejemplo, en la fiestas para celebrar a Huitzilopochtli, los indios guardaban la costumbre de no comer sino tzoalli (harina de amaranto) con miel y estaba prohibido tomar agua. Sobre esta costumbre Durán dice lo siguiente: “...y asi escondian el agua á los niños y auisauan a los que tenian usso de raçón que no bebiesen pues hauian comido tzoalli por que bendria la ira de aquel dios sobre ellos y moririan lo qual guardauan tan rigurossamente y tan por el extremo como los judios el no comer carne de puerco...”. Ibíd., v. II, “Tratado de los ritos y ceremonias”, cap. III, p. 44.

60 Sobre la vestimenta que los mexicas usaban en la migración Durán dice que eran “unas camisas largas hasta el suelo como lobas judaicas, el qual traje yo lo alcancé y hoy dia entiendo se usa entre los macehuales”. Ibíd., v. I, “Tratado de historia”, cap. III, p. 73.

61 Ibíd., v. I, “Tratado de historia”, cap. I, pp. 59-60. 
No obstante, la prueba que confirmaba sus sospechas se la ofreció su propia experiencia como misionero. En efecto, la insistencia de los indios novohispanos por regresar a sus antiguas prácticas después de haber recibido el bautismo y la incansable lucha de los misioneros por lograr una efectiva evangelización de inmediato le recordaron las constantes faltas del pueblo de Israel, relatadas en el mismo Salmo 105, así como el repetido perdón de Yavé al recordar la alianza con su pueblo.

\section{LA IMAGEN POSITIVA DEL INDIO}

En la Historia de las Indias la imagen negativa que Durán se forjó de los judíos también recayó sobre los indios, quienes fueron considerados como hombres de bajo entendimiento, idólatras, supersticiosos e hipócritas. ${ }^{62}$ Sin embargo, es claro que dichos calificativos sólo fueron usados cuando se refirió a sus prácticas religiosas. En realidad, como mencionamos anteriormente, en nuestro fraile arraigó un entrañable orgullo tanto por los naturales como por las tierras novohispanas. Por ejemplo, sobre el gobierno y orden en que vivían los mexicas tenochcas el dominico dijo lo siguiente: "si en los ritos é idolatrías mostraron ceguedad y engaño diabólico, al menos en las cosas de gobierno y pulicía, sujecion y reverencia, grandeça y autoridad, ánimo y fuerças, no hallo quien los sobrepuje...”. ${ }^{63}$ Además, sobre los habitantes de Tetzcoco, pueblo en donde vivió de niño, Durán dijo que era gente “...en todo esmerada y pulitica, avisada y retórica, de linda lengua y elegante y pulida, cuya pulicia en el hablar puede tener la prima como Toledo en España...". ${ }^{64}$ Y finalmente, sobre algunas regiones de la Nueva España, como Cuauhnahuac (Cuernavaca, Morelos), consideró que era "tierra por cierto la mas bella y deleitosa que hay en medio mundo, que si no fuera por el mucho calor que en ella hace, era otro paraiso terrenal...". 65

Con todo, quizá la mejor forma en que el dominico expresó su identificación con la tierra americana fue tratando de explicar que dicho territorio no había sido olvidado de Dios, es decir, que los siglos que permaneció incógnita para los hombres no lo había estado para el Creador. Para resolver este asunto, Durán tuvo que trascender la simple identificación de los indios como judíos y mostrar las pruebas de que el Todopoderoso había incluido a la Nueva España en el plan divino de salvación. Esto lo logró planteando la existencia de una evangelización en América anterior a la llegada de los españoles. 


\section{TOPILTZIN Y LA PREEVANGELIZACIÓN}

Durán recurrió al libro de Isaías para señalar el castigo que le fue impuesto a las tribus de Israel por su idolatría. ${ }^{66}$ En ese mismo texto se señala lo siguiente: "En aquel día de nuevo la mano del Señor redimirá al resto del pueblo, a lo que reste de Asur y de Egipto, de Patros, de Cus, de Elam, de Sanaar, de Jamat y de las islas del mar. Alzará su estandarte en las naciones, y redimirá a los dispersos de Israel...” (Isaías 11:11-12). Como podemos observar, la profecía incluyó a las tribus llevadas en cautiverio a Asiria (Asur), por lo cual no sería descabellado pensar que nuestro autor la tuviera en mente para plantear que los indios-judíos, quienes habían sido castigados por su idolatría, también lograrían la redención de sus almas.

Así, el dominico comenzó a plantear la posibilidad de una evangelización en América anterior a la llegada de los españoles a partir del siguiente personaje:

Antes que empecemos á tratar de los Dioses en particular, de los ritos y cerimonias que se les hacian quiero tratar de un gran varon que aportó a esta tierra, de su vida religiosa, del culto que enseñaba, de donde los mexicanos, teniendo noticia del, se incitaron á componer cerimonias y cultos, á adorar ydolos, edificar altares y templos y a ofrecer sacrificios. ${ }^{67}$

En la memoria náhuatl, Topiltzin, uno de los gobernantes de Tula Xicocotitlan, y Quetzalcóatl, el dios serpiente emplumada, suelen fundirse en una misma figura. ${ }^{68}$ No obstante, en la Historia de las Indias Durán trató de establecer una clara distinción entre ambos personajes. De Quetzalcóatl, señaló que era "dios de los mercaderes", ${ }^{69}$ identificándolo directamente con su advocación Yacatecuhtli. ${ }^{70}$ Pero la cita que hemos retomado se refiere a un hombre ("gran varón”) y a su vida religiosa. Ese personaje es Topiltzin. ${ }^{71}$

Nuestro cronista menciona que Topiltzin "fue una persona muy benerable y religiosa á quien ellos — los toltecas - tuvieron en gran beneracion y le honraban y reberenciaban como á persona santa”. ${ }^{72}$ Como podemos notar,

66 Ibíd., v. I, “Tratado de historia”, cap. I, p. 54.

67 Ibíd., v. II, “Tratado de los ritos y ceremonias”, cap. I, p. 17.

68 Por ejemplo, en los Anales de Cuauhtitlan se le nombra Quetzalcóatl Topiltzin o Topiltzin Ce Ácatl Quetzalcóatl. Ver Anales de Cuauhtitlan [1570], p. 8.

69 Durán, op. cit., v. II, “Tratado de los ritos y ceremonias”, cap. VI, p. 70.

70 Ibíd., v. II, “Tratado de los ritos y ceremonias”, cap. VI, p. 74.

71 Ídem.

72 Ibíd., v. II, “Tratado de los ritos y ceremonias”, cap. I, p. 17. 
esta cita destaca principalmente la gran espiritualidad del personaje, al grado de caracterizarlo como un santo y, por lo tanto, objeto de veneración.

Posteriormente, Durán ofreció su descripción física: “demostraba ser hombre de edad: la barba larga, entre cana y roja: la nariz algo larga con algunas ronchas en ella, o algo comida: alto de cuerpo: el cabello largo, muy llano, sentado con mucha mesura". ${ }^{73}$ En este caso, es notorio que las características físicas que le atribuyó a Topiltzin lo diferenciaban notablemente de los indígenas.

Por último, el dominico describió su comportamiento moral: "Estaba siempre recojido en una celda orando, el qual pocas veces se dexava ver: era hombre muy austinente y ayunador: bibia castamente y muy penitenciero: tenía por exercicio el edificar altares y oratorios por todos los barrios y poner ymagenes en las paredes". ${ }^{74}$

Textos de tradición indígena como los Anales de Cuauhtitlan o la columna en español del Códice florentino, publicada como Historia general de las cosas de Nueva España, describen un comportamiento similar para Topiltzin-Quetzalcóatl. ${ }^{75}$ Sin embargo, como señala Miguel Pastrana Flores, las características que Durán atribuyó a este personaje también eran propias de "una vida ejemplar dentro de las normas cristianas". ${ }^{76}$

Con las tres descripciones anteriores —espiritual, física y moral-, el dominico sentó las bases para identificar a Topiltzin con un personaje concreto y propio de su bagaje cultural. Sobre éste no es necesario especular, él mismo nos dice de quién se trata:

Las açañas y maravillas de Topiltzin y de sus hechos heroycos son tan celebrados entre los indios y tan mentados y cassi con apariencia de milagros, que no se que me atreva á afirmar ni escribir de ellos, sino que en todo me sujeto á la correccion de la santa yglesia catolica, porque aunque me quiera atar al sagrado evangelio que dice por San Marcos, que mandó Dios á sus sagrados apostoles que fuesen por todo el mundo y predicassen el evangelio á toda criatura, prometiendo á los que creyessen y fuesen batiçados la bida eterna, no ossare afirmar en que este baron fuese algun apostol bendito. ${ }^{77}$

Ídem.

Ídem.

Por ejemplo, los Anales de Cuauhtitlan dicen: "En este [año] 2 acatl edificó Topiltzin Ce Acatl Quetzalcóatl su casa de ayunos, lugar de su penitencia y oración”, Anales de Cuahtitlan, p. 8. y la Historia general de las cosas de Nueva España dice: "Quetzalcóatl fue estimado y tenido por dios, y lo adoraban de tiempo antiguo en Tulla” y "Quetzalcóatl hacía penitencia punzando sus piernas y sacando la sangre con que manchaba y ensangrentaba las puntas e maguey, y se lavaba a media noche en una fuente que se llamaba Xippacoya...”. Sahagún, Historia general de las cosas de Nueva España [1577], v. I, pp. 308-309. Estas virtudes eran las apreciadas en un buen sacerdote.

Pastrana, Historias de la Conquista, p. 236.

Durán, op. cit., v. II, “Tratado de los ritos y ceremonias”, cap. I, p. 18. 
Aunque Durán menciona someter su opinión a la corrección de la Iglesia católica, es incuestionable su intención de hacer recaer sobre Topiltzin "la sospecha de haber sido un antiguo preevangelizador". ${ }^{78}$ Los tres aspectos de su descripción sirvieron al dominico para plantear esta posibilidad. De ahí se entiende que destacara la espiritualidad del personaje, que pusiera énfasis en la ejemplaridad de su comportamiento moral y que le adjudicara un aspecto físico que poco tenía que ver con los indígenas.

Posteriormente nos dice el dominico que

...gran fuerça me hace su bida y otras á pensar que, pues estas eran criaturas de Dios, racionales y capaces de la bien abenturança, que no las dejaría sin predicador, y si le hubo fue Topiltzin, el qual aportó á esta tierra, y segun la relacion del se da era cantero que entallaba imagenes en piedra y las labraba curiosamente, lo qual lemos del glorioso Santo Tomas, ser Oficial de aquel arte, y tambien sabemos aver sido predicador de los indios. ${ }^{79}$

Varias cosas importantes podemos destacar de este pasaje; en primer lugar, que Durán expresó la certeza de que los indios eran criaturas de Dios; después, que consideró que tenían la capacidad racional necesaria para recibir el Evangelio y, finalmente, que Dios dispuso a Topiltzin-santo Tomás como predicador en estas tierras. En este caso, para incluir a los naturales en la universalidad de la redención de las almas, nuestro cronista hizo explícito el haber recurrido al evangelio de san Marcos 16:15, en donde Jesús encarga a sus discípulos dar a conocer la buena nueva por todo el mundo. ${ }^{80}$

No obstante, para identificar a Topiltzin con santo Tomás, Durán no se basó exclusivamente en el Nuevo Testamento, sino que se apoyó en el apócrifo Hechos de Tomás, en donde se le atribuye al apóstol el haber predicado en la India y el ser cantero de oficio (HchTom 1:1-3). En función de ese texto reinterpretó las características que la historiográfica de tradición indígena le atribuía a Topiltzin-Quetzalcóatl, como el haber inventado todas las llamadas "artes mecánicas", ${ }^{81}$ entre las que se encontraba el trabajo en cantera. Sobre esto comparto la opinión de Lafaye, quien señala que en Durán debió nacer el siguiente cuestionamiento: "Si los indios resultaron innumerables, y el Nuevo Mundo pareció inmenso, ¿cómo admitir que Jesús hubiese olvidado lo que en aquel entonces se suponía que era la mayor parte del mundo y la más poblada, con el reparto de la humanidad que hizo entre sus apóstoles: ite el docte omni creatura?” Lafaye, op. cit., p. 235.

8 Sahagún, op. cit., v. I, p. 308. 
Para lograr que la figura de santo Tomás encajara mejor con el gobernante indígena, Durán enfatizó que "Topiltzin era un hombre adbenediço de tierras extrañas" ${ }^{2}$ e insistió en su carácter de predicador, señalando que "él y sus dicipulos salian á predicar por los pueblos y se subian á los cerros á predicar y sus voces se oyan de dos y tres leguas como sonido de trompeta". ${ }^{83}$ Como podemos notar, para el dominico los toltecas no fueron únicamente los habitantes de un lugar llamado Tula, sino los discípulos del apóstol santo Tomás, es decir, creyentes de la doctrina cristiana. ${ }^{84}$

Una vez que dejó bien perfilada la identificación de Topiltzin-santo Tomás, Durán buscó las pruebas de su labor evangelizadora en estas tierras y la primera que encontró fue la presencia de la cruz. Sobre esto nos dice:

Passando Topiltzin por todos estos pueblos que e dicho, dicen que yba entallando en la peñas cruces y ymagenes, y preguntandoles donde se podria ver para satisfacerme, nombraronme ciertos lugares donde lo podría ber, y uno en la çapoteca; y preguntando á un español que se via allado por allí, si aquello fuese verdad, me certifico con juramento quel avia bisto un crucifixo entallado en una peña... ${ }^{85}$

Existieron en el mundo indígena representaciones cruciformes asociadas tanto a los cuatro rumbos del universo como al árbol cósmico. El europeo, por analogía, vio en ellas a la cruz cristiana y, por lo tanto, las interpretó como signos de una preevangelización. ${ }^{86}$ Así, si en la interpretación de Durán Topiltzin era santo Tomás, resultaba lógico atribuirle a este personaje la difusión de dicho símbolo.

Fueron muchos los elementos cristianos que Durán creyó descubrir entre las prácticas religiosas de los indios. ${ }^{87}$ Mencionar todos desbordaría las pretensiones de este trabajo, así que sólo aludiremos a uno más que consideramos especialmente significativo: árbol de Tlaloc] se soleniçaba en nombre de padre que quiere decir tota, para que sepamos que reuerenciauan al padre y al hijo y al espiritu santo y deçian tota, topiltzin y yolometle los quales bocablos quieren decir nuestro padre y nuestro hijo y el coraçon de anbos haciendo fiesta a cada vno en particular y a todos tres en vno donde se nota la noticia que huuo de la trinidad entre esta gente..”. Durán, op. cit., v. II, “Tratado de los ritos y ceremonias”, cap. VIII, p. 95. 
...tambien me dixo un yndio biejo que passando el Papa por Ocuituco les avia dejado un libro grande, de quatro dedos de alto, de unas letras, y yo movido con deseo de aver este libro, fui é Ocuituco y rogue á los yndios, con toda omillad del mundo, me lo mostrasen y me juraron que abrá seis años que le quemaron por que no acertavan á ler la letra, ni era como la nuestra y que temiendo no les causase algun mal le quemaron, lo cual me dio pena porque quiça nos diera satisfecho de nuestra duda que podria ser el sagrado evangelio en lengua hebrea, lo qual no poco reprehendí á los que lo mandaron quemar. ${ }^{88}$

Para el dominico, la existencia del evangelio en lengua hebrea hubiera sido la prueba irrefutable de una evangelización en América anterior a la llegada de los españoles, por eso, además de intentar comprobar personalmente su existencia, sintió una enorme pena al descubrir que el sustento material de su hipótesis había sido destruido.

Así, ante la imposibilidad de obtener la prueba definitiva de sus sospechas, Durán intentó darles fundamento a partir de las propias fuentes indígenas:

Queriendome confirmar en si esto era verdad, pregunte á un yndio biejo que me le bendieron por letrado en su ley natural de Coatepec, el qual murio desta enfermedad, que me dixese si aquello era assi que alli tenia escrito y pintado; y como no saben dar relacion, si no es por el libro de su aldea, fue á su cassa y truxo una pintura, que á mi me parecieron ser mas hechiços que pintura. El qual tenia alli cifrada por unos caracteres yn ynteligibles toda la vida del papa y de sus dicipulos y me la relató como el otro, y mejor, de que no poco contento quede, y se aventajó un poco; con mas, enseñandome la figura de Topiltzin que quando celebraba las fiestas se ponia aquella corona de plumas que en la pintura bimos, á la manera que se ponen la mitra los obispos en la cabeça quando dicen missa. ${ }^{89}$

Como podemos notar, el dominico consideró que las obras de tradición indígenas confirmaban cabalmente sus sospechas de haber sido Topiltzinsanto Tomás el predicador en estas tierras. Para ello, otorgó total crédito a la información de los antiguos códices prehispánicos, la cual le fue descifrada por los hombres más sabios entre los indios: los ancianos.

Con los anteriores ejemplos, Durán consideró satisfecha su sospecha del trabajo apostólico realizado por santo Tomás en América. No obstante, al dominico le faltaba explicar dos asuntos que eran ineludibles: En primer lugar, si los indios habían recibido una evangelización en tiempos de santo 
Tomás ¿qué justificaba la conquista de estas tierras? y, en segundo lugar, ¿por qué era necesaria una "nueva” o "segunda" evangelización? La respuesta a estas dos interrogantes nuevamente la construyó a partir de lo que las fuentes indígenas relataban acerca de Topiltzin-Quetzalcóatl.

Contra Topiltzin y contra sus dicipulos se levantó gran persecucion, que oy certifica que se levantó guerra contra ellos por que el número de gente que abía tomado aquella ley era mucha y los que seguian la predicacion y exemplo de aquel santo baron y de sus dicípulos. El caudillo desta persecucion, segun dicen, fué Tezcatlipoca, el qual finjiendo ser bajado del cielo para aquel efecto, fingía también hacer milagros, juntando dicípulos y gente maligna para molestar aquellos barones de buena bida y desterrallos de la tierra. ${ }^{90}$

Entre los naturales la caída de Tula se explicaba a partir de la lucha entre los dioses Quetzalcóatl y Tetzcatlipoca. Esta disputa tenía que ver con la influencia cíclica de los dioses sobre el mundo de los hombres, y en obras como los Anales de Cuauhtitlan o la Historia general de las cosas de Nueva España quedó representada en el relato de los numerosos engaños con los que el dios del espejo humeante intentó acabar con el dominio de Quetzalcóatl haciéndolo faltar a sus obligaciones religiosas. ${ }^{91}$

Esta información fue interpretada por Durán como la lucha “entre los designios salvadores de la providencia y las tentativas perversas del enemigo”. ${ }^{9}$ Según narra el dominico, Topiltzin-santo Tomás y sus discípulos estaban desempeñando una exitosa labor evangelizadora en estas tierras, sin embargo, esto despertó la molestia de Tezcatlipoca (el demonio), quien por medio del engaño y con ayuda de sus legiones ("gente maligna”) consiguió expulsar al predicador de América.

El imperio que el demonio logró establecer con la expulsión del apóstol sirvió a Durán para explicar la supuesta persistencia idolátrica de los indios.

90

Los Anales de Cuauhtitlan, por ejemplo, narran que tanto Quetzalcóatl como Huémac fueron engañados por Tetzcatlipoca. Al primero lo emborrachó y lo incitó a tener relaciones sexuales con su hermana Quetzalpétlatl en un templo; con ello llegó la expulsión del dios y la destrucción de Tollan. Y de Huemác dice que fue engañado por Yáotl ("el enemigo”, una de las advocaciones de Tetzcatlipoca), por lo cual tuvo relaciones con "las diablesas” mientras se desempeñaba como sacerdote de Quetzalcóatl. Anales de Cuauhtitlan, pp. 8-10 y 1213. La Historia tolteca-chichimeca destaca que la caída de Tula se debió a las lujuriosas exigencias de Huémac, quién pidió a los nonoalcas una mujer de cuatro cuartas de ancho de cadera. Historia tolteca-chichimeca [1546], p. 133; por su parte, Sahagún narra tanto la borrachera de Quetzalcóatl propiciada por Tetzcatlipoca, como la falta del gobernante Huémac tras haber satisfecho los apetitos sexuales de su hija, la cual había caído enferma de calentura al ver desnudo a un vendedor de chiles llamado Tohuenyo, quien era una manifestación de Tetzcatlipoca. Sahagún, op. cit., v. I, Libro tercero, cap. V, pp. 310 y 312.

92

Lafaye, op. cit., p. 90. 
No obstante, dicha idea le fue aún más útil para justificar la conquista y evangelización de estas tierras. Esto queda claro en la siguiente profecía que Topiltzin-santo Tomás hizo a sus discípulos:

[les pronosticó] la benida de una gente estraña, que de las partes de oriente aportaria á esta tierra, con un traxe estraño y de diferentes colores, bestidos de pies á cabeza y con coberturas en las cabeças y que aquel castigo les avia de inbiar Dios en pago del mal tratamiento que le avian hecho y la afrenta con que le echavan; con el qual castigo, chicos y grandes perecerian, no pudiendo excaparse de sus manos de aquellos, sus hijos, que avian de benir á destruyllos aunque se metiesen en las cuebas y en las cavernas de la tierra, y que de allí los sacarian y allí los arian á perseguir á matar estas gentes luego pintaron en sus escrituras á que estas gentes quel papa les profetiçaba para tener memoria della y esperar el suceso, como despues lo bieron cumplido en la benida de los españoles. ${ }^{93}$

En este caso, interpretando el dominio cíclico de los dioses, el dominico puso en boca de Topilzin-santo Tomás la profecía del sometimiento de estas tierras, su justificación fue acabar con el imperio del demonio, pues a la conquista armada, a la cual otorgó un carácter providencial, seguiría una "nueva” o "segunda" labor evangelizadora, ${ }^{94}$ de la cual él formaba parte en ese momento.

\section{CONSIDERACIONES FINALES}

Incluir a los indígenas americanos en el devenir cristiano universal fue una constante en la producción historiográfica del siglo XVI sobre el Nuevo Mundo. Sin embargo, cada cronista construyó explicaciones distintas acordes con las posibilidades que les brindaba el campo epistemológico de su tiempo. A lo largo de este trabajo hicimos evidente el fondo teológico del que echó mano el dominico Diego Durán. El análisis dio cuenta de que su manejo de textos sagrados no se limitó al conocimiento de los escritos canónicos, como el Viejo y el Nuevo Testamento, sino de un uso razonado de escritos que quedaron fuera del canon, como sucedió con 4 Esdras y con Hechos de Tomás. A partir de este corpus de escritos ortodoxos y apócrifos, el autor dio solidez a dos ejes interpretativos que articularon su Historia de las Indias: la identificación de los naturales con judíos y la existencia de una preevangelización en América iniciada por Topiltzin-santo Tomás. Con el 
primer eje, Durán pudo caracterizar a los indios como criaturas de Dios, como hombres racionales y como seres capaces de recibir el Evangelio; y con el segundo le otorgó un carácter de irrevocable a la participación de los naturales, y de América en general, en el plan de salvación.

Así mismo, el análisis nos permitió observar que Durán conocía ampliamente las fuentes indígenas y que dio crédito al conocimiento resguardado en los códices y la tradición oral, sin embargo, esto sucedió principalmente cuando su contenido le permitía establecer analogías con la tradición cristiana para dar sustento a su explicación de la historia de los indios.

A diferencia de otros cronistas de su época, en Durán es identificable un entrañable cariño por su tierra americana a la que llegó cuando era niño. Las manifestaciones más básicas de ese sentimiento fueron expresadas en las elocuentes descripciones, tanto de la capacidad intelectual de los indios, como de las bondades naturales de la Nueva España. Sin embargo, la expresión más acabada quedó plasmada en su empeño por incorporar a su tierra americana en el mismo rumbo histórico que Dios había dispuesto para todo buen pueblo cristiano. Ese esfuerzo de intelección fue clave para que el novohispano pudiera superar la aparente ambivalencia en la que vivía, al reconocerse como heredero cultural e histórico de España la vieja y al mismo tiempo como "hijo de la Nueva España". ${ }^{95}$ Es por eso que en este trabajo planteamos que el proceso del criollismo es nodal para entender la obra del dominico. De hecho, no es casualidad que la hipótesis de la labor apostólica de Topiltzin-santo Tomás fuera retomada por criollos de la talla de Carlos de Sigüenza y Góngora (1645-1700) y de fray Servando Teresa de Mier (17631827).

No es posible demostrar que la obra de Durán tuvo un impacto directo en los escritos de los dos intelectuales arriba mencionados, pues en ellos no hay referencias a la Historia de las Indias, a la que se le perdió la pista después de que Juan de Tovar la aprovechara (1587) para redactar la segunda versión de su Relación del origen de los indios que habitaban esta Nueva España. Sin embargo, ya sea por influencia directa o porque Sigüenza y Mier llegaron a planteamientos análogos a partir de un fondo teológico similar, lo significativo es que en la obra de Durán ya tenemos algunos de los argumentos que posteriormente retomaron estos dos criollos, no sólo para defender la inclusión de su patria criolla en el camino de la redención, sino para construir un discurso político que elevara su importancia espiritual al nivel de otras naciones, ${ }^{96}$ tal como sucedió con el sermón de 1794 en el que Mier vinculó a santo Tomás con la virgen de Guadalupe.

O’Gorman, El heterodoxo guadalupano, v. I, p. 34. 
Si pensáramos al criollismo como un río, alguien podría situar a Durán en los pequeños manantiales que lo formaron en su nacimiento; sin embargo, la metáfora no daría cuenta ni de la naturaleza del cuerpo de agua ni de la complejidad del proceso ontológico que representa como figura retórica. Un río no es constante en su curso, en algunas partes es estrecho, rápido y accidentado; en otras es amplio, lento y apacible. De la misma forma, las expresiones de la toma de conciencia del ser novohispano fueron afines con las circunstancias históricas en que se situó cada uno de sus actores.

\section{Bibliografía}

Acosta, José de, Historia natural y moral de las Indias, en que trata de todas las cosas notables del cielo, elementos, metales, plantas y animales dellas y los ritos y ceremonias, leyes y gobierno de los indios, 2 ed., México, Fondo de Cultura Económica, 1979 (Biblioteca Americana).

Alberro, Solange, El águila y la cruz. Orígenes religiosos de la conciencia criolla. México, siglos XVI-XVII, México, El Colegio de México/Fondo de Cultura Económica, 1999, 192 pp., láms. (Sección de Obras de Historia, Fideicomiso Historia de las Américas, Serie Ensayos).

Alvarado Tezozómoc, Fernando de, Crónica mexicáyotl, 3 ed., trad. de Adrián León, México, unam, Instituto de Investigaciones Históricas, 1998.

Anales de Cuauhtitlan, en Códice Chimalpopoca (Anales de Cuauhtitlan y Leyenda de los soles), 3 ed., trad. de Primo Feliciano Velázquez, México, unam, Instituto de Investigaciones Históricas, 1992 (Primera Serie Prehispánica, 1).

Sagrada Biblia, $40^{a}$ edición, versión directa de las lenguas tradicionales por Eloino Nacar Fuster y Alberto Colunga Cueto, Madrid, Editorial Católica, 1980 (Biblioteca de Autores Cristianos).

Camelo Arredondo, Rosa y José Rubén Romero Galván, "Estudio preliminar”, en Diego Durán, Historia de las Indias de Nueva España e islas de Tierra Firme, v. 1, México, Consejo Nacional para la Cultura y las Artes, 1995, v. I, pp. 15-47.

, “Fray Diego Durán”, en Historiografía novohispana de tradición indígena, (coord. José Rubén Romero Galván), México, unAM: Instituto de Investigaciones Históricas, 2003, pp. 229-257.

Castillo, Cristóbal del, Historia de los mexicanos y de otros pueblos e historia de la conquista, traducción y estudio introductorio de Federico Navarrete Linares, México, Consejo Nacional para la Cultura y las Artes, 2001 (Cien de México).

Catálogo de la colección de Don Juan Bautista Muñoz, 3 v., Madrid, Real Academia de Historia, 1954.

Codex Azcatitlan, 2 v., trad. de Leonardo López Luján y Dominique Michelet, París, Bibliothèque Nationale de France/Société des Américanistes, 1995. 
Colston, Stephen y Carlos Paredes, "Un servicio de fray Diego Durán a la Inquisición”, Boletín del Instituto Nacional de Antropología e Historia, 3a época, núm. 29, 1980, pp. 41-44.

“Correspondencia entre los padres José de Acosta y Juan de Tovar”, Históricas, núm. 63, 2002, pp. 31-34.

Dávila Padilla, Agustín, Historia de la fundación y discurso de la provincia de Santiago de México de la orden de predicadores, México, Academia literaria, 1955.

Durán, Diego, Historia de las Indias de Nueva España e islas de Tierra Firme, 2 v., México, Consejo Nacional para la Cultura y las Artes, 1995 (Cien de México).

—- Historia de las Indias de Nueva España e islas de Tierra Firme, Manuscrito original, Biblioteca Nacional de España, en:

http://bdh-rd.bne.es/viewer.vm?id=0000169486\&page=1

Fernández del Castillo, Francisco, "Fray Diego Durán. Aclaraciones históricas”, Anales del Museo Nacional de Arqueología, Historia y Etnografía, 4 a época, v. III, 1925, pp. 223-229.

Frost, Elsa Cecilia, La Historia de Dios en las indias. Visión franciscana del Nuevo Mundo, México, Tusquets, 2002.

García, Gregorio, Origen de los indios del Nuevo Mundo, México, Fondo de Cultura Económica, 1981 (Biblioteca Americana).

García Martínez, Florentino, “Authority of 4 Ezra \& Jewish Origin of American Indians”, en Florentino García Martínez, Between philology and theology: contributions to the study of ancient Jewish interpretation, editores Hindy Nejman y Eibert Tigchelaar, Leiden, Brill, 2012 (Supplements to the Jornal for the study of Judaism, 164).

Gliozzi, Giuliano, Adamo e il nuovo mondo. La nascita dell'antropologia come ideología coloniale: dalle genealogie bibliche alle teorie razzaili (15001700), Florencia, La Nouva Italia, 1977.

Hanke, Lewis, en The First Social Experiments in America: A Study of the Development of Spanish Indian Policy in the Sixteenth Century, Cambridge, Harvard University Press, 1935.

Historia tolteca-chichimeca, 2a. ed., México, Fondo de Cultura Económica, 1989 (Colección Puebla).

Iglesia, Ramón, "Sobre el estado actual de las ciencias históricas”, en El hombre Colón y otros ensayos, 2a ed., México, Fondo de Cultura Económica, 1994 (Sección de obra de Historia).

Lafaye, Jacques, Quetzalcóatl y Guadalupe. La formación de la conciencia nacional en México, trad. de Ida Vitale y Fulgencio López Vidarte, México, Fondo de Cultura Económica, 1992 (Sección de obras de Historia).

León-Portilla, Miguel, "El indio visto por los frailes del siglo XVI", en Estudios de Cultura Náhuatl, núm. 41, 2010, pp. 281-295. 
Manrique, Jorge Alberto, “Del barroco a la ilustración”, en Historia general de México (versión 2000), México, El Colegio de México, 2000, pp. 431-488.

Mapa Sigüenza, en Pintura de la peregrinación de los culhuaque-mexitin (Mapa de Sigüenza): Análisis de un documento de origen tenochca, Estado de México, El Colegio de Mexiquense/CONACUlTa/INAH, 2006.

Máynez Vidal, Pilar, Fray Diego Durán. Una interpretación de la cosmovisión mexicana, México, unAm: Escuela Nacional de Estudios Profesionales Acatlán, 1997.

O’Gorman, Edmundo, “Sentido y significación histórica de la Apologética historia sumaria”, en Bartolomé de las Casas, Apologética historia sumaria, 2 v., México, UnAM: Instituto de Investigaciones Históricas, 1967, v. I, p. LVIIILXXIX.

, Meditaciones sobre el criollismo, México, Condumex, Centro de Estudios de Historia de México, 1970.

—_, "Prólogo”, en Fernando de Alva Ixtlilxóchitl, Nezahualcóyotl Acolmiztli, 1402-1472, México, Gobierno del Estado de México, 1972, pp. 11-21.

— El heterodoxo guadalupano, en Servando Teresa de Mier, Obras completas, 3 vols., México, unAm: Coordinación de Humanidades, 1981 (Nueva Biblioteca Mexicana, 81-83).

—_, "La conciencia histórica en la edad Media”, en Historiología, teoría y práctica, México, unAm, 1999, pp. 29-66.

Pastrana Flores, Miguel, Historias de la Conquista. Aspectos de la historiografía de tradición náhuatl, México, unAM: Instituto de Investigaciones Históricas, 2004 (Serie Teoría e Historia de la Historiografía, 2).

Paz, Octavio, "Prefacio”, en Jacques Lafaye, Quetzalcóatl y Guadalupe. La formación de la conciencia nacional en México, $2^{\mathrm{a}}$ ed., trad. de Ida Vitale y Fulgencio López Vidarte, prefacio de Octavio Paz, México, Fondo de Cultura Económica, 1992, pp. 11-26, láms. (Sección de obras de Historia).

Peperstraete, Sylvie, La "Chronique X”: reconstitution et analyse d'une source perdue fondamentale sur la civilisation Aztèque, d'après l'Historia de las Indias de Nueva España de D. Durán (1581) et la Crónica Mexicana de F.A. Tezozomoc (ca. 1598), Oxford, Archaeopress, 2007 (BAR International Series 1630$)$.

Romero Galván, José Rubén, “La historia según Chimalpain” en Journal de la Société des Américanistes, París, Musée de L’homme, 1998, pp. 183-195.

Rozat Dupeyron, Guy, Indios imaginarios e indios reales, en los relatos de la conquista de México, México, Tava, 1993, XIII+197 pp.

Sahagún, Bernardino de, Historia general de las cosas de Nueva España, 3a. ed., 3 v., México, Consejo Nacional para la Cultura y las Artes, 2000 (Cien de México). 
Sandoval, Fernando, "La relación de la conquista de México en la historia de Fray Diego Durán”, en Estudios de historiografía de la Nueva España, México, El Colegio de México, 1945, pp. 51-90.

Tira de la peregrinación (Códice Boturini), Arqueología mexicana, edición especial códices, núm. 26, México, 2008.

Torquemada, Juan de, Primera parte de los veinte i un libros rituales i monarchia indiana, con el origen y guerras, de los Indios Occidentales de sus poblaciones, descubrimiento, conquista y conversion y otras cosas maravillosas de la mesma tierra, 3 v., México, Porrúa, 1969 (Biblioteca Porrúa, 41-43).

Ulloa, Daniel, Los predicadores Divididos. Los dominicos en la Nueva España, siglo XVI, México, El Colegio de México: Centro de Estudios Históricos, 1977 (Nueva serie, 24).

Vásquez Galicia, Sergio Ángel, La Historia de las Indias de Diego Durán y los albores del criollismo, México, unAM: Facultad de Filosofía y Letras, 2005 (tesis para obtener el grado de licenciado en Historia).

—_, Mexico Tenochtitlan, raíz, ombligo y corazón de esta máquina mundial. El criollismo en la Historia de las Indias de Diego Durán, (en prensa). 